\title{
A comparative analysis of the processing speed between video game players and non-players
}

\author{
Helena Pardina-Torner ${ }^{1}$, Xavier Carbonell ${ }^{2}$ \& Marcos Castejón $^{2}$ \\ ${ }^{1}$ Universitat de Barcelona \\ ${ }^{2}$ Universitat Ramon Llull (Barcelona)
}

Received: 23 oct 2018

Accepted: 4 march 2019

A comparative analysis of the processing speed between video game players and non-players

\begin{abstract}
Summary. Processing speed is an essential cognitive skill in our everyday lives, and, as such, it has been extensively studied. However, there is still uncertainty as to when and how, with appropriate training, an individual's processing speed can be increased across a range of tasks without compromising accuracy. While playing action video games, individuals are required to process information at high speed, forcing the players to make instantaneous decisions and execute responses. Therefore, it seems worth investigating the possibility that the use of video games might serve as an efficient training mechanism for individuals wishing to speed up their overall perceptual reaction times (without sacrificing accuracy). Thus, the aim of the present study is to analyze the processing speed of video game players and compare it to that of non-video game players in order to determine whether these two groups display any significant differences. To this end, a questionnaire collecting data on gaming habits and sociodemographic data, as well as two tests that evaluate processing speed, were administered to a sample of 50 university students enrolled in different degree programmes. The scores of the two groups were then compared, and (taking into account possible experimental error) the results showed that video game players have a shorter reaction time than non-video game players and that neither of the groups made more mistakes than the other.
\end{abstract}

Keywords: video games; processing speed; learning transfer; comparative analysis; reaction time

Un análisis comparativo de la velocidad de procesamiento entre jugadores de videojuegos y no jugadores

Resumen. La velocidad de procesamiento es una habilidad cognitiva esencial en la vida cotidiana y, como tal, ha sido ampliamente estudiada. Sin embargo, aún existe incertidumbre sobre cuándo y cómo, con el entrenamiento adecuado, la velocidad de procesamiento de una persona puede aumentarse en una variedad de tareas sin comprometer la precisión. Mientras juegan videojuegos de acción, los individuos tienen que procesar información a alta velocidad, hecho que obliga a los jugadores a tomar decisiones y a ejecutar respuestas instantáneas. Por consiguiente, vale la pena investigar la posibilidad de que el uso de videojuegos pueda servir como un mecanismo de entrenamiento eficiente para las personas que desean acelerar sus tiempos de reacción de percepción generales (sin sacrificar la precisión). Por lo tanto, el objetivo del presente estudio es analizar la velocidad de procesamiento de jugadores de videojuegos y compararla con la de no-jugadores para determinar si estos dos grupos muestran diferencias significativas. Para este fin, se administró un cuestionario que recopilaba datos sobre hábitos de juego y datos sociodemográficos, así como dos pruebas que evaluaban la velocidad de procesamiento, a una muestra de 50 estudiantes universitarios matriculados en diferentes programas de especialidades universitarias. A continuación, se compararon las puntuaciones de los dos grupos y, teniendo en cuenta el posible error experimental, los resultados mostraron que los jugadores de videojuegos tienen un tiempo de reacción más corto que los que no lo son sin verse comprometidos por un mayor índice de errores puesto que ninguno de los grupos cometió más errores que el otro.

Paraules clau: videojuegos; velocidad de procesamiento; transferencia de aprendizaje; análisis comparativo; tiempo de reacción

Correspondence

Helena Pardina Torner

University of Barcelona

helenapt1@blanquerna.url.edu 


\section{Introduction}

In recent years, both society at large and the scientific community in particular have devoted a significant amount of interest to theories and studies of video games and their potential impact on the minds of the individuals that play them. The sensationalistic media headlines on the topic are often replete with stories about the possible effects that video games have on the brain, variously claiming that they can "damage" it or "boost" its power, but this coverage often disregards the complexities and/or limitations of the studies or sources it cites, creating a confusing overall picture of the effects of gaming on the brain (Bavelier, et al. 2015; Castejon, Carbonell, \& Fuster, 2015).

While much is often made of the supposed negative effects of gaming, the possibility that playing video games may promote certain positive developments is discussed less often. However, the literature does feature a number of publications along these lines, some of them with explanations of how to harness this knowledge about gaming for educational and rehabilitation purposes. For example, some video game studies have found positive effects on visuospatial cognition (Spence \& Feng, 2010) and prosocial behaviour (Greitemeyer \& Osswald, 2010), while others acknowledge the video games' potential as tools to effectively teach a variety of skills, including algebra and geometry (Corbett, Koedinger, \& Hadley, 2001). Most video game enthusiasts spend many hours playing, submerged in this intense activity, especially in action or first-person shooter video games. These two popular genres have several common properties, such as: unpredictability, intense and high-speed activity, a high perceptual, cognitive and motor load, the need to choose between multiple action plans, and an emphasis on peripheral processing (Oei \& Patterson, 2013). Such exceptional activity has the potential to alter both brain and behaviour, and the possible applications of this phenomenon should not be ignored (Spence \& Feng, 2010). Academic study of video games' potential may contribute not only to an improved understanding of the mechanisms of learning, but may also point the way towards new approaches to teaching various skills (Spence \& Feng, 2010).

This existing research demonstrating that video games can have beneficial effects falls into several different categories. The bulk of the studies that have examined perception and spatial cognition, and focused on action video games, found that playing this type of game yields a wide range of behavioural benefits, including enhancements in low-level vision (Bavelier et al., 2015), a better conscious control of attention (Chisholm \& Kingstone, 2012), cognitive control (Anguera, et al., 2013), an increased capacity for attention and task-switching (Nuyens, Kuss, LopezFernandez, \& Griffiths, 2018), a faster processing speed (Mishra, Zinni, Bavelier, \& Hillyard, 2011), and improved cognitive flexibility (Colzato, van Leeuwen, van den Wildenberg, \& Hommel, 2010). Researchers have found that action games influence various aspects of perceptual processing (Dye, Green, \& Bavelier, 2009), including multiple object tracking (Oei \& Patterson, 2013), spatial resolution (Green \& Bavelier, 2007), and central and peripheral attention skills (Bavelier et al., 2015). Perceptual and attentional skills improve as a consequence of gamers' constant practice of scanning the screen to detect small changes, focusing their attention on certain areas and targeting them in a short amount of time (Bavelier et al., 2015). What remains unclear is if such abilities represent general improvements in cognitive functioning or whether they are specific skills that could be transferred only to other similar tasks, such as the perceptual skills needed by air traffic controllers, for example (Bavelier et al., 2015).

Meanwhile, a number of properly controlled training studies have repeatedly demonstrated a causal link between playing video games and the enhancement of certain kinds of abilities. Hence, it is not just that the people who choose to play video games have naturally better perceptual skills and that's why they pick them up. The capacity to improve one's abilities through practice has obvious practical ramifications, from rehabilitation of visual skills in individuals with amblyopia to the training of surgeons (Bavelier et al., 2015). Although fewer studies have examined the potential positive effects of video games on of social behaviour, at least one publication found the playing of pro-social games to be associated with a short-term effect that may lead to more 'helping' behaviour. For example, children who had played more pro-social games early in the school year demonstrated increased helpful behaviours later in the same school year (Bavelier et al., 2015). Additionally, many online games seem specifically designed to reward effective cooperation, support, and helping behaviour between players (Ewoldsen et al., 2012). Therefore, players learn social skills and prosocial behaviour while playing, which may then be translated to their broader peer and family relations outside the gaming environment (Gentile \& Gentile, 2008; Gentile et al., 2009; Granic, Lobel \& Engels, 2014).

So, in summary, the evidence on the possible link between playing video games and enhanced cognition and perception has been well documented (Granic et al., 2014; Nuyens et al., 2018; Oei \& Patterson, 2013; Spence \& Feng, 2010). Results from multiple studies indicate that action video game exposure is primarily associated with increased visuospatial cognition (Ferguson, 2007). Playing action video games leads to improvements in sensory, perceptual, and spatial cognitive functions that go beyond the limits of the specific expertise acquired in the game (Spence \& Feng, 2010); the size of the attentional visual field is also increased (Boot, Blakely, \& Simons,2011; Feng, Spence, \& Pratt, 2007; Granic et al., 2014; Green \& Bavelier, 2003, 2006; Spence, Feng, \& Marshmann, 2009), and other functional improvements have been observed in basic spatial tasks (Green \& Bavelier, 2003, 2006, 2007; 
Li, Polat, Makous \& Bavelier, 2009) and complex spatial tasks (Feng et al., 2007).

Playing video games can alter the brain, but the durability over time of these changes remains a question. However, the results of numerous studies do show that these alterations can actually persist for a long period of time (Feng et al., 2007; Jaeggi et al., 2011; Li et al., 2009; Spence et al., 2009,). Frequent action game players outperform non-gamers on a variety of perceptual and cognitive measures (Boot et al., 2008), and some studies suggest that video game training enhances cognitive performance on tasks other than those specific to the game (Boot et al., 2011). Such findings have profound scientific and educational implications. Perhaps most importantly, examining these effects may inspire the development of new methodologies to investigate the brain mechanisms that are responsible for these effects along with multiple other possibilities (Ferguson, 2007). Secondly, the potential transfer of enhanced capacities from video game training to other aspects of cognition is a highly novel idea, as it contradicts the extensive literature showing that training in one task rarely improves performance in others (Ball et al., 2002; Granic et al., 2014; Hertzog, Kramer, Wilson, \& Lindenberger, 2009; Owen et al., 2010).

Gaming is a relatively new field of study, and therefore, opposing or alternative explanations for this phenomenon are bound to emerge. A frequent criticism levelled at the studies that have recorded differences between the cognitive results of video game players (VGPs) and non-players (NVGPs) is that these differences may not be caused by gaming itself (Boot et al., 2011; Langer, Djikic, Pirson, Madenci, \& Donohue, 2010). Instead, people may be drawn to action games because they have the types of abilities required to excel at these games, or there might be another factor that influences both cognitive abilities and gaming. A good example of a factor that may have an influence on the results of several studies is expectation. If gamers are recruited to participate in a study because of their gaming experience, they might expect to perform well because of their expertise, and the belief that one will perform well can heavily influence real performance, even on measures as basic as visual acuity (Langer et al., 2010).

When suggesting that video game training enhances cognitive performance on certain tasks, it is important to mention the genre of the game in question, as the potential benefits that can be achieved through playing certain video games are, of course, dependent of the specific task requirements in that game (Bavelier et al., 2015). This is why the possible beneficial or harmful effects that an individual may sustain are determined by the characteristics of both the individual and the game (Bavelier et al., 2015). Nonetheless, studies have mostly focused on just two genres of video-games: violent video games and action video games, and very few other genres have been the subject of nearly as much psychological experimentation as these two kinds of games (Arsenault, 2009).
That is an unfortunate situation, given the nearly limitless diversity and range of video games. Popular genres include action, adventure, dance, driving, fighting, maze, music, puzzle, role playing, simulation, sports and strategy games (Apperley, 2006; Spence \& Feng, 2010). The breadth of video game diversity is visible not only in the sheer number of genres, but also in the new variations that are born as hybrids of these existing genres. Although some individual games fit comfortably within one category or another, most of them are difficult to pigeonhole, and others clearly occupy more than one category. So, in addition to the variations already existing within games of the same genre, there is an even greater difference between the genres themselves, which is exactly what makes each of them distinctive. Each genre of game requires different skills to be successful in meeting the challenges and coping with the tricky situations encountered through the game. Some video games involve problem solving and planning, whereas others demand fast reflexes and superior visuomotor coordination, or value more the social and interpersonal skills. All in all, one can find multiple video games that stimulate a range of cognitive functions using different approaches, and collectively they can help us to exercise almost all of the cognitive and social skills required in our daily lives. However, it seems that only a few genres have the potential to actually affect the cognitive processes of the players (Spence \& Feng, 2010).

The games that can exert such an effect are likely have a number of characteristics. Firstly, they tend to require a series of progressively more accurate and challenging judgments and actions, taken at high speed. Secondly, these games force users to focus their attention closely and to overcome a number of increasingly jarring distractions, a practice that allows gamers to increase their working memory spans. Finally, these games often provide a training in a pro-social context, posing increasingly harder cognitive challenges to users. Games that meet these criteria have been found to drive positive neurological changes in the brain systems that support these behaviours (Bavelier et al., 2015).

The potential benefits of video games are worthy of attention partly because the nature of these games has changed dramatically in the last decade. Although exclusively violence-driven games do still exist, the spectrum of genres and types of video games nowadays is marked by the prevalence of increasingly complex, diverse, realistic and social games (Granic, et al., 2014). With this in mind, it can be said that there is at least some solid evidence to suggest that the positive consequences of playing action games may outweigh the negative ones (Ferguson, 2007; Ferguson, 2010).

A number of studies have explored the possible causal links between video game playing and enhanced cognition and perception examining how these games might provide benefits to their players (Dye, Green, \& Bavelier, 2009; Granic et al., 2014; Nuyens et al. 2018; 
Oei \& Patterson, 2013; Spence and Feng, 2010). In this study, the focus will be on processing speed as a cognitive skill. This skill may be affected by playing video games (Dye, Green \& Bavelier, 2009), much like any other cognitive skills mentioned above, including visual acuity (Green \& Bavelier, 2007) and visuospatial cognition (Ferguson, 2007). When playing video games, especially those in the action genre that require rapid processing of sensory information and take fast reactions in order to succeed, gamers have to make decisions and execute responses at a far greater pace than we usually do in our everyday lives (Matthew, Dye, Green, \& Bavelier, 2009). To ensure and reinforce decision making and fast responses, delays in processing within games are often penalized or have severe consequences, providing a large incentive for players to react faster or to keep up a certain speed. It seems reasonable, then, to assume that such mental stimulation can result in the honing of one's cognitive abilities, which may lead to their improvement. Studies on the matter have concluded that video games players exhibit faster processing speed (Castel, Pratt, \& Drummond, 2005; Mishra et al. 2011; Nuyens et al., 2018) than non-players. Following this train of thought, the next step is to wonder whether this reduction in the reaction time (RT) can be generalized to other tasks beyond gaming (Matthew et al. 2009). Were this the case, it could mean that gamers are more impulsive and prone to making errors (anticipatory errors, as they are responding incorrectly because they do not wait for enough information to become available before they respond), as fast decisions typically translate into an increased number of mistakes made (Matthew et al. 2009).

One exception to this rule is that the performance of individuals who are significantly trained in such fast-paced tasks is improved on these in particular. However, little transfer of improved performance to new tasks is observed in these cases, limiting the benefits of the training to that specific task (Pashler \& Baylis, 1991), with no significant transfer from game training to other aspects. It is worth highlighting, however, that flexible or integrated training regimens that require constant switches from one processing priority to another and continual adjustments to new task demands have been argued to lead to greater and farther-reaching transferability to other kinds of activities (Bherer et al., 2005). Action video games would seem most likely to meet these criteria for flexible training.

The possibility that playing video games may affect perceptual and cognitive skills has attracted a great deal of interest lately. Most past studies have compared video game players (VGPs) to novice or non-video game players (NVGPs), using tasks that measure reaction time (RT) in order to draw conclusions about performance. Although this is usually not the primary focus of these studies, they invariably show that VGPs seem to be overall faster than those who do not play such games (Bialystok, 2006; Castel, Pratt, \& Drummond, 2005;
Greenfield et al., 1994; Matthew et al. 2009, Nuyens et al. 2018).

The purposes of this study are: a) to analyse the processing speed of VGPs (H1: VGPs are faster than NVGPs); b) to analyse the errors made by the participants (H2: VGPs make more mistakes than NVGPs); and c) to identify any differences between action video game players and those who prefer other game genres (H3: action VGPs have better results than the other VGPs).

\section{Methods}

\section{Participants}

The participants were 50 university students, 25 of whom were VGPs and 25 NVGPs. They ranged in age from 18 to 25 , with a mean age of $22.14(\mathrm{SD}=1.54)$, and $50 \%$ were men. They attended a number of different university institutions in Barcelona, and each was enrolled in one of a number of degree programmes: Psychology (28\%), Business Administration and Management in English (11\%), Video-game Development (GameDev) (10\%), Engineering (10\%) and Law (5\%). Those participants with more than five years of experience and an average of more than five hours a week spend playing video games were placed in the VGP group, while the others were put in the NVGP group.

\section{Instruments}

A questionnaire was used to collect data on sociodemographic characteristics: gender, age, gaming experience, game habits and preferred video game genre. To assess the cognitive processing speed of each individual, two tests were used. Both tests are part of the Wechsler Adult Intelligence Scale (WAIS-III) and can be found in the Processing Speed Index (PSI). Both neuropsychological tests, described below, are useful in the measurement of cognitive abilities such as processing speed, associative memory and graphomotor speed.

- Digit Symbol-Coding: Subjects are given $120 \mathrm{sec}-$ onds to copy as many numbers from 1-9 as they can, pairing each with a symbol. Participants are given digit-symbol pairs (such as: $1 /-, 2 / \perp \ldots 7 / \Lambda$, $8 / \mathrm{X}, 9 /=$ ) followed by a list of digits. Within these two minutes, the participants are asked to draw symbols below each of the corresponding digits as fast as possible, doing as many as they can. The number of correct and incorrect symbols written within the allotted time is measured, and a score is produced.

- Symbol Search: The subjects must, within $120 \mathrm{sec}-$ onds, search for one of two symbols in a line of five, then mark "YES" if the symbol can be found in the segment of five symbols or "NO" if not. The participants have to do as many segments as they can within the time given. 


\section{Procedure}

The tests were always administered in the presence of an examiner, who explained the procedure and monitored the time. No personal information was requested, making impossible to connect any of the data from the questionnaires to academic or personal records and therefore ensuring the anonymity of the participants. Participants signed an informed consent before doing the tests. The subjects did not receive any monetary nor academic reward for their participation.

\section{Data Analysis}

The data were analysed using IBM SPSS Statistics V.21.0, and descriptive statistics, mean comparisons and bivariate correlations were done. Normality checks were run on the data through the Shapiro-Wilk test, and because the sample was not normally distributed, the Mann-Whitney U test was carried out to analyse the possible significant differences between: a) the test results of VGPs and NVGPs, b) the number of errors made by VGPs and NVGPs, c) and Action VGPs and Other VGPs in terms of test results and number of errors.

To determine whether there were any significant correlations between the test results, the errors made and the participants' age, correlations were calculated using Spearman's rho test.

\section{Results}

The demographic differences between Video game players (VGPs) and Non-Video game players (NVGPs) are shown in Table 1. Both groups were made up of a proportional number of men and women ranging in age from 18 to 25 , with a very similar mean age in the two groups as well. There was also little difference between the groups in terms of the university studies the members were pursuing, with participants from a range of different degree programmes present in both groups.

Descriptive statistics of the scores of Digit SymbolCoding (Test 1) and Symbol Search (Test 2) and the number of errors made by VGPs in comparison of NVGPs are presented in Table 2 . The results of Test 1 show significant differences between VGPs and NVGPs $(p<.05)$, with VGPs scoring higher. The results of Test

Table 1. Gender, age and studies of Video game players (VGPs) and Non-Video game players (NVGPs)

\begin{tabular}{|c|c|c|c|c|c|}
\hline & & \multicolumn{2}{|r|}{ VGP } & \multicolumn{2}{|c|}{ NVGP } \\
\hline & & n (\%) & $\mathrm{M}(\mathrm{SD})$ & n (\%) & $\mathrm{M}(\mathrm{SD})$ \\
\hline \multirow[t]{2}{*}{ Gender } & Male & 13 & - & 11 & - \\
\hline & Female & 12 & - & 14 & - \\
\hline \multirow[t]{2}{*}{ Age } & Male & - & $22.54(1.51)$ & - & $22.36(1.57)$ \\
\hline & Female & - & 21.75 (1.66) & - & $21.92(1.49)$ \\
\hline Studies & $\begin{array}{l}\text { Game Dev } \\
\text { Psychology } \\
\text { ADE } \\
\text { Engineering } \\
\text { Law }\end{array}$ & $\begin{array}{l}10(40 \%) \\
4(16 \%) \\
4(16 \%) \\
4(16 \%) \\
3(12 \%)\end{array}$ & - & $\begin{array}{l}0(0 \%) \\
10(40 \%) \\
7(28 \%) \\
6(24 \%) \\
2(8 \%)\end{array}$ & - \\
\hline
\end{tabular}

Table 2. Comparison between Tests and Errors

\begin{tabular}{lllll}
\hline & $\begin{array}{l}\text { VGP } \\
(\mathbf{n}=25)\end{array}$ & $\begin{array}{l}\text { NVGP } \\
(\mathbf{n}=25)\end{array}$ & & \\
& Mean & Mean & U-Mann & $\boldsymbol{p}$ (2-tailed) \\
\hline Test 1 & 29.60 & 21.44 & 210,000 & .045 \\
\hline Test 2 & 29.89 & 21.16 & 204,000 & .034 \\
\hline Errors & 24.40 & 26.60 & 285,000 & .577 \\
\hline
\end{tabular}

Table 3. Correlations

\begin{tabular}{llllll}
\hline & M & SD & Test 2 & Errors & Age \\
\hline Test 1 & 12.04 & 2.89 & $.646^{\star *}$ & -.089 & -.085 \\
\hline Test 2 & 14.08 & 5.49 & & -.232 & -.231 \\
\hline Errors & 1.38 & 1.71 & & & .110 \\
\hline Age & 22.14 & 1.53 & & & \\
\hline Note. ${ }^{* *} p<.001$ & & & & &
\end{tabular}

Table 4. Video game Genre Comparison: Action vs Others

\begin{tabular}{lllll}
\hline & $\begin{array}{l}\text { Action } \\
(\mathbf{n}=\mathbf{1 4}) \\
\text { Mean }\end{array}$ & $\begin{array}{l}\text { Other } \\
(\mathbf{n}=\mathbf{1 1}) \\
\text { Mean }\end{array}$ & U-Mann & $p$ (2-tailed) \\
\hline Test 1 & 13.29 & 12.64 & 73,000 & .825 \\
\hline Test 2 & 14.39 & 11.23 & 57,000 & .279 \\
\hline Errors & 13.79 & 12.00 & 66,000 & .526 \\
\hline
\end{tabular}

2 also showed significant differences between VGPs and NVGPs $(p<.05)$, with VGPs again obtaining better results than NVGPs. No significant differences were found regarding the errors made by the two groups $(p>.05)$.

There was no direct correlation between the speed of the participants as measured by the tests and the errors they made. Likewise, neither speed nor errors made were correlated the participants' ages (Table 3). But, as expected, the study found a positive correlation between the participants' results for test 1 and those for test $2(r=0.64, p=.000)$, as both tests are designed to assess the participants' processing speed.

Regarding the genre of video game VGPs tend to play the most often (Table 4), the results didn't indicate any significant differences $(p>0.05)$ between Action VGPs and Other-genre VGPs on any of the variables.

\section{Discussion}

The objective of this study was to analyze the processing speed of regular video game players and compare these results with those of non-video game players. Regarding the first objective, the results of this study showed that in both tests VGPs responded more quickly than NVGPs did on both tasks, confirming the hypothesis (H1: VGPs are faster than NVGPs) on increased processing speed in this first group. These results are consistent with previous studies (Bialystok, 2006; Castel, Pratt, \& Drummond, 2005; Matthew et al., 2009) that have shown that VGPs have a faster reaction time than NVGPs.

The second hypothesis (H2: VGPs make more mistakes than NVGPs) was tested to see if the increased speed of processing observed on the group of VGPs represent "trigger-happy" behaviour. In other words, 
it was thought that VGPs might respond faster but make more errors. Response accuracy did not differ for the two groups. VGPs were found to be faster but not more prone to making mistakes than NVGPs, therefore disproving the hypothesis. Both the results of this study and those of a study by Matthew et al. (2009) fail to confirm the hypothesis of shorter reaction time leading to more error-prone performance.

In terms of the comparison between players of different game genres, this study found no difference in terms of the reaction time of action and non-action VGPs. The third hypothesis (H3: action VGPs have better results than the other VGP) is therefore rejected. These results are similar of those found by Spence and Feng (2010), which showed that action games are not the only ones that can have a significant cognitive impact. Other games that require progressively more accurate and challenging judgments and actions at high speed, focused attention and training in a prosocial context can also drive positive neurological changes in the brain systems that support these behaviours (Bavelier et al., 2015; Greitemeyer \& Osswald, 2010).

There was no direct correlation between the age of the participants and their results and errors made in the tests. The only positive correlation found was between Tests 1 and 2, which confirms that both tests evaluate the processing speed of the participants.

Beyond the clear theoretical interest of the study, it is important to underline the great possible practical benefits that a training programme focused on processing speed may have, as it may result in learning that can be transferred from the video frame and have reallife educational applications (Belchior, 2007; Sue et al., 2014) or be used for the purposes of rehabilitation (Bavelier et al., 2015). Our current job market requires certain professionals (i.e., policemen, emergency room technicians, etc.) to display a mastery of a very specific set of skills that would benefit from a cognitive training using processing speed, a training regimen in which the professional must face social challenges or stressful decisions (Dye, Green, \& Bavelier, 2009) or where speed and precision are requirements to correctly develop the task requested. In the fields of rehabilitation or education, such training programmes could be beneficial for individuals with a damaged (or slower-than-normal) processing speed, such as victims of brain trauma or the elderly. Thanks to the advance of technology (and gaming development), it is nowadays more possible than ever to plan activities that are fun and entertaining, while also ensuring that users spend time on tasks with an educational or rehabilitative impact (Bavelier et al., 2015).

It is important to acknowledge the limitations of this study. The results found are representative of a small sample size and thus it would be desirable to try to replicate the same study with a bigger sample. For future research, one recommendation would be to measure the impulsivity of the participants, as it would be of interest to assess the effects of this trait and anal- yse a possible correlation or causal relationship between errors and impulsivity (Billieux et al., 2015; Matthew et al., 2009; Puerta-Cortés, Panova, Carbonell, \& Chamarro, 2017). Specifically, considering this variable would reveal whether: a) impulsive individuals are more prone to making mistakes and b) VGPs are more impulsive than NVGPs. In short, future research should investigate the effect of impulsivity, because it may be a variable affecting the results. Future research should also focus on the difference in reaction time between action VGPs and non-action VGPs. Because of the kind of perceptual and cognitive skills needed, action (Dye, Green, \& Bavelier, 2009), driving, maze, and puzzle genres are often found most likely to have a significant impact on one's cognitive abilities (Kühn, et al., 2014; Spence \& Feng, 2010). An analysis of other genres such as strategy, sports or platforms would be a meaningful study. Another element that must be taken into account for future studies is motivation. This study's sociodemographic questionnaire (administered before the main tests) asked participants about their gaming habits and other issues. These questions could lead participants to believe that their abilities with regard to video games would be an important factor that would be tested, and this belief might have influenced their scores. Although they were told from the beginning that their gaming skills were not being evaluated (but their processing speed was), it would be advisable in future studies for the questionnaire to be completed after the participants have performed the tests so that factors such as motivation or expectations will not influence the results. This could very possibly be an explanation to why Psychology students (who ended mostly in the NVGPs group) made more mistakes than the others. Asking participants to fill in the questionnaire at the end might be a way to confirm this hypothesis or to disprove it.

In conclusion, VGPs seem to have a better reaction time than NVGPs, without being compromised by a greater index of errors. This is true regardless of the genre of video game they prefer to play. This study reveals that video games seem to have a positive impact on the processing speed of players, and even if it is too early to draw definitive conclusions, the results suggest that playing video games is an advisable activity with a lot of potential and that games could have multiple applications in different fields such as education or rehabilitation.

\section{Acknowledgments}

To ENTI (UB) for allowing their students to partake in this study.

\section{References}

Anguera, J. A., Boccanfuso, J., Rintoul, J. L., Al-Hashimi, O., Faraji, F., Janowich, J., Kong, E., Larraburo, Y., Rolle, C., Johnston, E., \& Gazzaley, A. (2014). Video game training enhances cognitive control in older 
adults. Nature, 501(7465), 97-101. doi:10.1038/nature12486

Apperley, T. (2006). Genre and game studies: Toward a critical approach to video game genres. Simulation \& Gaming, 37 (1), 6-23. doi:10.1177/1046878105282278

Arsenault, D. (2009). Video game genre, evolution and innovation. Eludamos. Journal for Computer Game Culture, 3(2), 149-176. Retrieved from: http://www. eludamos.org/index.php/eludamos/article/view/65

Ball, K., Berch, D. B., Helmers, K. F., Jobe, J. B., Leveck, M. D., Marsiske, M., et al. (2002). Effects of cognitive training interventions with older adults: A randomized controlled trial. Journal of the American Medical Association, 288, 2271-2281.

Bavelier, D., Green, C. S. \& Han, D. H., Renshaw, P. F., Merzenich, M. M., \& Gentile D. A., (2015). Brains on video games. Nature Reviews Neuroscience, 12(12), 763-768. doi: 10.1038/nrn3135.Brains

Belchior, P. (2007). Cognitive training with video games to improve driving skills and driving safety among older adults. Changes, 68, 1-209.

Bherer, L., Kramer, A. F., Peterson, M. S., Colcombe, S., Erickson, K., \& Becic, E. (2005) Training effects on dual-task performance: Are there age-related differences in plasticity of attentional control? Psychology and Aging, 20(4), 695-709. doi: 10.1037/08827974.20.4.695

Bialystok, E. (2006). Effect of bilingualism and computer video game experience on the Simon task. Canadian Journal of Experimental Psychology, 60(1), 68-79.

Billieux, J., Thorens, G., Khazaal, Y., Zullino, D., Achab, S., \& Van der Linden, M. (2015). Problematic involvement in online games: A cluster analytic approach. Computers in Human Behavior, 43, 242-250. doi:10.1016/j.chb.2014.10.055

Boot, W., Blakely, D., \& Simons, D. (2011). Do action video games improve perception and cognition? Frontiers in Psychology 2(226). doi: 10.3389/fpsyg.2011.00226

Boot, W. R., Kramer, A. F., Simons, D. J., Fabiani, M., \& Gratton, G. (2008). The effects of video game playing on attention, memory, and executive control. Acta Psychologica, 129(3), 387-398. doi:10.1016/j.actpsy.2008.09.005.

Castejon, M., Carbonell, X., \& Fuster, H. (2015). Entrenamiento de la percepción rotacional con videojuegos [Training of rotacional perception with videogames]. Communication papers: media literacy \& gender studies, 4(6), 74-80.

Castel, A. D., Pratt, J., \& Drummond, E. (2005). The effects of action video game experience on the time course of inhibition of return and the efficiency of visual search. Acta Psychologica, 119(2), 217-230. doi:10.1016/j.actpsy.2005.02.004

Chisholm, J. D., \& Kingstone, A. (2012). Improved top-down control reduces oculomotor capture: The case of action video game players. Attention, Perception, \& Psychophysics, 74(2), 257-262. doi:10.3758 / s13414-011-0253-0.

Colzato, L. S., van Leeuwen, P. J. A., van den Wilden- berg, W. P. M., \& Hommel, B. (2010). DOOM'd to switch: Superior cognitive flexibility in players of first person shooter games. Frontiers in Psychology, (APR). doi:10.3389/fpsyg.2010.00008

Corbett, A. T., Koedinger, K., \& Hadley, W. S. (2001). Cognitive tutors: From the research classroom to all classrooms. In P. S. Goodman (Ed.), Technology enhanced learning: Opportunities for change (pp. 235-263). Mahwah, NJ, US: Lawrence Erlbaum Associates Publishers.

Dye, M. W. G., Green, C. S., \& Bavelier, D. (2009). The development of attention skills in action video game players. Neuropsychologia, 47(8-9), 1780-1789. doi:10.1016/j.neuropsychologia.2009.02.002

Ewoldsen, D. R., Eno, C. A., Okdie, B. M., Velez, J. A., Guadagno, R. E., \& DeCoster, J. (2012). Effect of playing violent video games cooperatively or competitively on susequent cooperative behavior. Cyberpsychology, Behavior, and Social Networking, 15, 277280. doi: 10.1089/cyber.2011.0308

Feng, J., Spence, I., \& Pratt, J. (2007). Playing an action video game reduces gender differences in spatial cognition. Psychological Science, 18(850-855).

Ferguson, C. (2007). The good, the bad and the ugly: A meta-analytic review of positive and negative effects of violent video games. Psychiatric Quarterly, 78(4), 309-316. doi:10.1007/s11126-007-9056-9

Ferguson, C. J. (2010). Blazing angels or resident evil? Can violent video games be a force for good? Review of General Psychology 2010, 14(2), 68-81. doi: 10.1037/ a0018941

Gentile, D. A. (2009). Pathological video-game use among youth ages 8-18: A national study. Psychological Science, 20, 594-602. doi:10.1111/j.1467-9280.2009.02340.x

Gentile, D. A., Anderson, C. A., Yukawa, S., Ihori, N., Saleem, M., Ming, L. K., \& Sakamoto, A. (2009). The effects of prosocial video games on prosocial behaviors: International evidence from correlational, longitudinal, and experimental studies. Personality and Social Psychology Bulletin, 35, 752-763. doi:10.1177/0146167209333045

Gentile, D. A., \& Gentile, J. R. (2008). Violent video games as exemplary teachers: A conceptual analysis. Journal of Youth and Adolescence, 9, 127-141. doi:10.1007/S10964-007-9206-2

Granic, I., Lobel, A., \& Engels, R. (2014). The benefits of playing video games. American Psychologist, 69(1), 66-78. doi:10.1037/a0034857

Green, C. S., \& Bevalier, D. (2003). Action video game modifies visual selective attention. Nature. 423, 534537. doi:10.1038/nature01647

Green, C. S., \& Bevalier, D. (2006). Effect of action video games on the spatial distribution of visuospatial attention. Journal of Experimental Psychology. Human Perception and Performance, 32(6), 1465-1478. doi:10.1037/0096-1523.32.6.1465

Green, C. S., \& Bevalier, D. (2007). Action-videogame experience alters the spatial resolution of vision. Psychological Science, 18(1), 88-94. doi:10.1111/j.1467-9280.2007.01853.x 
Greenfield, P. M., DeWinstanley, P., Kilpatrick, H., \& Kaye, D. (1994). Action video games and informal strategies for dividing visual attention. Journal of Applied Developmental Psychology, 15(1), 105-123.

Greitemeyer, T., \& Osswald, S. (2010). Effects of prosocial video games on prosocial behaviour. Journal of Personality and Social Psychology, 98(2), 211-221. doi: 10.1037/a0016997

Hertzog, C., Kramer, A. F., Wilson, R. S., \& Lindenberger, U. (2009). Enrichment effects on adult cognitive development. Psychological Science in the Public Interest, 9, 1-65. doi: 10.1111/j.1539-6053.2009.01034.x

Langer, E., Djikic, M., Pirson, M., Madenci, A., \& Donohue, R. (2010). Believing is seeing: using mindlessness (mindfully) to improve visual acuity. Psychological Science. 21(5), 661-6. doi: 10.1177/0956797610366543

Li, R. J., Polat, U., Makous, W., \& Bavelier, D. (2009). Enhancing the contrast sensitivity function through action video game training. Nature Neuroscience, 12(5), 549-551. doi: 10.1038/nn.2296

Jaeggi, S. M., Buschkuehl, M., Jonides, J., \& Shah, P. (2011). Short and long-term benefits of cognitive training. Proceedings of the National Academy of Sciences of the United States of America, 108(25), 10081-6. doi:10.1073/pnas.1103228108

Kühn, S., Gleich, T., Lorenz, R. C., Lindenberger, U., \& Gallinat, J., (2014). Playing Super Mario induces structural brain plasticity: gray matter changes resulting from training with a commercial video game. Molecular Psychiatry, 19(2), 265-71. doi: 10.1038/ mp.2013.120

Matthew W. G., Dye, M., Green, C., \& Bavelier, D. (2009). Increasing speed of processing with action video games. Current Direction in Psychological Science, 18(6), 321-326. doi:10.1111/j.1467-8721.2009.01660.x

Mishra, J., Zinni, M., Bavelier, D., \& Hillyard, S. A. (2011). Neural basis of superior performance of action videogame players in an attention-demanding task. Journal of Neuroscience, 31(3), 992-998. doi:10.1523/ JNEUROSCI.4834-10.2011.

Nuyens, F., Kuss, D. J., Lopez-Fernandez, O., \& Griffiths, M. D. (2018). The empirical analysis of non-problematic video gaming and cognitive skills: A systematic review. International Journal of Mental Health and Addiction, 17, 389-414. doi:10.1007/s11469-018-9946-0

Oei, A., Patterson, M. (2013). Enhancing cognition with video games: A multiple game training study. PLOS ONE, 8(3). doi:10.1371/journal.pone.0058546

Owen, A. M., Hampshire, A., Grahn, J. A., Stenton, R., Dajani, S., Burns, A. S., Howard, R. J., \& Ballard, C. G. (2010). Putting brain training to the test. Nature, 465, 775-779. doi: 10.1038/nature09042

Pashler, H., \& Baylis, G. C. (1991). Procedural learning: I. Locus of practice effects in speeded choice tasks. Journal of Experimental Psychology: Learning, Memory, and Cognition, 17(1), 20-32. doi: 10.1037/02787393.17.1.20

Puerta-Cortés, D. X., Panova, T., Carbonell, X., \& Chamarro, A. (2017). How passion and impulsivity influence a player's choice of videogame, intensity of playing and time spent playing. Computers in Human Behavior, 66, 122-128. doi:10.1016/j.chb.2016.09.029

Spence, I., \& Feng, J. (2010). Video games and spatial cognition. Review of General Psychology, 14(2), 92-104. doi:10.1037/a0019491

Spence, I., Yu, J. J. J., Feng, J., \& Marshman, J. (2009). Women match men when learning a spatial skill. Journal of Experimental Psychology: Learning, Memory, and Cognition, 35, 1097-1103. doi: 10.1037/a0015641.

Sue, D., Ray, P., Talaei-Khoei, A., Jonnagaddala, J., \& Vichitvanichphong, S. (2014). Assessing video games to improve driving skills: A literature review and observational study. JMIR Serious Games, 2(2), e5. doi:10.2196/games.3274 